\title{
Wind Turbines to Power Telecommunication Systems: A Case Study in Sicily
}

\author{
Antonio Messineo ${ }^{1, *}$, Vincenzo Franzitta ${ }^{2}$ and Marco Trapanese ${ }^{3}$ \\ ${ }^{I}$ Faculty of Engineering \& Architecture, Kore University of Enna, Italy \\ ${ }^{2}$ Department of Energy and Environmental Researches, University of Palermo, Italy \\ ${ }^{3}$ Department of Electrical Engineering, University of Palermo, Italy
}

\begin{abstract}
The ever increasing problems related to air pollution and the difficulties for power lines to reach inaccessible areas are pushing to find new solutions for powering telecommunications equipments (TLC). The renewable energy systems, although relatively expensive, have the required characteristics. The purpose of this work is to find a solution based on a low power wind turbine to serve a real telecommunication site located near Palermo, the main city of Sicily (Italy).
\end{abstract}

Keywords: Wind turbine, TLC, radio station, renewable energy.

\section{INTRODUCTION}

As an ever increasing number of people around the world become connected by fixed and mobile telecommunications networks, the challenges related to providing electricity to these expanding networks are becoming greater as well. Energy costs are among the largest operation expenses for network operators, and energy consumption from telecommunication networks is an increasing contributor to global greenhouse gas (GHG) emissions.

Furthermore, powering mobile communications infrastructure is particularly challenging in developing countries where many base stations are in remote areas with limited mains grid power. Often these off-grid mobile towers are powered by diesel generators with low efficiency and related consumption of fossil fuels and greenhouse gases emissions.

Electrical power systems have been traditionally designed to take energy from high-voltage levels, and distribute it to lower voltage level networks. There are large generation units connected to transmission networks. In these networks there is a bulk transport of electricity, with central coordination of control (modulating outputs of generators). Demands are passive and uncontrollable, connected to distribution networks. Distribution systems are also passive and, in the lower levels of voltage, radial in operation. They are designed to receive power from transmission systems and distribute it to customers, generally with unidirectional flows, although with some interconnections.

In contrast, in a power system composed of distributed energy resources (DERs), much smaller amounts of energy are produced by numerous small, modular energy conversion units, which are often located close to the point of end use.

\footnotetext{
*Address correspondence to this author at the Faculty of Engineering \& Architecture, Kore University of Enna, Italy; Tel: +39 091238 61908; Fax: +39091 484425; E-mail: antonio.messineo@unikore.it
}

In the last decade many countries have started the process of liberalization of their electric systems, opening access to transmission and distribution grids. The process has been accompanied by a rapidly growing presence of small generators of various technologies, some of which in the form of renewable energy sources (RESs).

As a result of the application of new technologies and the deregulation in the electric power sector, a new identity appeared in the electric power system map known as "distributed generation" (DG). DG is related to the use of small generating units installed close to load centers.

Different DG technologies are implemented to fulfill the requirements of a wide range of applications. These applications and technologies differ according to the load requirements (thermal needs, stand-alone or grid-connected electrical power, size and requirements of power quality, environmental issues in the site, etc.). Some of these applications are listed below:

- rural and remote applications (stand alone),

- standby sources to supply power for sensitive loads during grid outages,

- combined heat and power (CHP) with injection of power into the network when the DG capacity is higher than its local loads,

- peak-load shaving,

- utility-owned DGs, to provide part of the main required power and support the grid by enhancing the system voltage profile, reducing the power losses, and improving the system power quality,

- grid connection to sell the electrical energy.

DG covers a broad range of technologies, including many renewable technologies that provide small-scale power at sites close to users. Some of them are: 
- reciprocating engines (internal combustion engines),

- gas turbines,

- microturbines,

- fuel cells,

- photovoltaic systems,

- thermoelectric solar plants,

- wind energy conversion systems (WECSs),

- biomass fuelled power plants,

- hydroelectric power plants.

Power generation systems that use renewable resources like sun, wind, organic matter, and geothermal Energy, have some advantages over traditional fossil-fuelled power generation systems. For example, most renewable power technologies do not produce greenhouse gases in the utilization phase and emit far less pollution compared to burning oil, coal, or natural gas to generate electricity. It is widely recognized than the greenhouse gas intensity in hydroelectrical systems is about $15 \mathrm{~g} \mathrm{CO}_{2} / \mathrm{kWhe}$ on average, $20 \mathrm{~g}$ $\mathrm{CO}_{2} / \mathrm{kWhe}$ in the case of wind turbines, and $100 \mathrm{~g}$ $\mathrm{CO}_{2} / \mathrm{kWhe}$ for photovoltaics, whereas in classical thermal systems burning natural gas it is around $577 \mathrm{~g} \mathrm{CO}_{2} / \mathrm{kWhe}$ (combined cycle) or $750 \mathrm{~g} \mathrm{CO}_{2} / \mathrm{kWhe}$ (open cycle) and in burning black coal the values are greater than $860 \mathrm{~g}$ $\mathrm{CO}_{2} / \mathrm{kWhe}$. Renewable energy technologies utilize free energy sources [1].

The application proposed in this paper is related to the utilization of RESs to power telecommunication systems. Nowadays, the ever increasing problems related to air pollution and the difficulties for power lines to reach inaccessible areas are pushing to find new solutions for powering telecommunications equipments (TLC). The renewable energy systems, although relatively expensive, have the required characteristics.

The equipments for telecommunications systems convert the energy they absorb into an electromagnetic signal through an antenna. Antennas are then devices acting as transducers to operate the processing of an electrical signal into electromagnetic energy radiated in free space (transmission antennas) or make the reverse conversion (receiving antennas). Transmission can be either broad-casting or directional: in the first case the antenna distributes the signal over an area large enough to reach the highest possible number of receivers, while the latter antennas are a radio link, i.e. link between two points reciprocally visible (direct vision).

An example of this type of transmission occurs in Base Transceiver Stations (SRB) for mobile phones. Mobile phone installations are widespread throughout the country; they are divided in several installations. Each station installed covers an area (named cell), whose size depends on the density of users: within towns, for example, the cells are of a few hundred meters, while in suburban areas are much larger.

The fixed cellular devices consist of antennas transmitting the signal to the phone and antennas receiving the signal transmitted by the phone.
The irradiating apparatuses are installed on towers or tall buildings, thus emitting the signal with low interference in their cell area, the portion of land covered is guaranteed by three groups of antennas (three cells) placed in different directions, such that the system is almost isotropic.

The installed power for each direction ranges from 72 watts, for a Total Access Communications System (TACS) system, to 25 watts for a Global System Mobile (GSM). The altitude of the installation site and the power and type of antennas used contribute significantly to limit the overall intensity of the electromagnetic field in the areas surrounding the plant.

The radio links are bidirectional links between two fixed stations carried by using microwave satellite dishes radiating electromagnetic energy in very narrow beams, both horizontally and vertically due to their high gain transmit signals over long distances.

These systems are then used to connect two distant points (antennas) without intervening obstacles, emitting the signal in a specific direction and with a high frequency. The connection can be made directly between two points on Earth; in this case one talks about terrestrial radio links.

Moreover, two distant points on earth via a satellite telecommunication can be connected, and in this case they are called satellite radio links. Being used for transmissions, the frequencies are in the Giga Hertz and therefore the wavelength is of the order of centimeters, so the antennas employed have to be necessarily parabolic, strongly directives for high gain.

In this paper the authors take into consideration a particular transmission station which is located on the top of a mountain in proximity of the town of Palermo, the main city of Sicily (Italy).

The site in question has some peculiar features that would make it suitable for the exploitation of a renewable energy source, mainly wind energy, for the production of the electric energy necessary to power the transmission station. In fact, the site is reachable only through a road which is uneven in several stretches. The existing power line is nowadays insufficient for the requirements of the radio transmission center, both for the dispatched power and for the frequent interruptions of the service, due to faults. Furthermore, the tension is often out of phase, above the limits imposed by regulations related to the technical features of the installed instrumentation. These drawbacks make the service unreliable and thus not acceptable for an operator that is in charge of supplying a public service like the mobile telephony. Finally, all the equipments of the transmission station work with direct current; for this reason it could be convenient to use a system in which the renewable energy is stored in a battery system (whose installation is moreover already foreseen in the transmission station, because they should be used in case of power surges or disconnections from the main power grid) which is also connected to the main power grid.

\section{DESCRIPTION OF THE RADIO TRANSMISSION STATION}

Radio station broadcasting consists of four circular parabolic antannae used for radio link, one of the diameter of 
$300 \mathrm{~cm}$, another one of a diameter of $240 \mathrm{~cm}$ and two $60 \mathrm{~cm}$ diameter. These are placed on a lattice and are connected to radio equipment PDH (Plesiochronous Digital Hierarchy) and SDH (Synchronous Digital Hierarchy) via signal transmission cables. The area affected by the installation has a dimension of approximately 70 square meters.

The area occupied by the installed station is 8.50 square meters $(2.90 \mathrm{~m} \times 2.93 \mathrm{~m}$ and $\mathrm{h}=2.40 \mathrm{~m})$ sufficient to accommodate three frames which are assembled telecommunications equipment (Siemens PDH, ADM, Alcatel SDH), a IES (Integrated Energy Station), two conditions knapsack, probes and all safety equipment and preparation for a room forsen by the standards of the Italian mobile operator.

Four parables are clamped by appropriate attacks on the truss supports, and are positioned at the center of 4 walls and they have orientation (up from ground level) as shown below:

- dish diameter $=60 \mathrm{~cm}$; tilt $45^{\circ}$ in direction of CariniPalermo - at $7 \mathrm{~m}$.

- dish diameter $=60 \mathrm{~cm}$; tilt $30^{\circ}$ in direction of the Island of Females- Palermo - at $8 \mathrm{~m}$.

- dish diameter $=240 \mathrm{~cm}$; tilt $76^{\circ}$ in direction of $\mathrm{Mt}$ Pellegrino - Palermo - at $5 \mathrm{~m}$.

- dish diameter $=300 \mathrm{~cm}$; tilt $221^{\circ}$ in direction of Mt Bonifato - Alcamo - at $4 \mathrm{~m}$.

The technical equipment is supplied by IES, which distributes electricity and protects lines of different users.It includes a section of the energy supply (AC/DC) and the batteries back up.

The main constituent parts of IES are: the cabinet, the rectifier modules, the programmable controller to manage the smooth functioning of the energy and climate control, battery back-up, instruments for distribution and protection of batteries and D.C. equipments, and the temperature sensors (battery, environment, external delivery air conditioners).

The connection between technical equipment and the parables is via cable transmission signal from $1 / 4$ inch housed in a special rack. All metal and electrical parts are earthed.

\subsection{Analysis of Energy Consumption of Radio Station Transmission}

The assessment of energy consumption of the radio station is the preliminary starting point for its characterization in terms of energy. Based on these data it was possible to propose a set of assumptions and actions on the station that allows energy savings by exploiting renewable energy sources.

The analysis of energy consumption was carried out on two different levels and in particular by:

- consultation of the electricity bills;

- assessment of the use of the electrical equipments.

\subsubsection{Evaluation of the Electricity Consumption Using the Electricity Bills}

Energy consumption of the station can be evaluated using electricity bills. Data were extrapolated from the readings of consumption reported in electricity bills, in particular those of 2008 were considered (Table 1). To make this type of study, it was considered appropriate to go back to the values of consumption for each month of the year.

Since the readings of the bills generally refer to bimonthly periods the procedure used to extrapolate the monthly consumption was the following: the consumption recorded in a given time interval was divided by the same reference period (in days) necessary to produce the average daily energy consumed in that time interval. Multiplying this quantity by the actual number of days falling in the month and proceeding in a similar manner for all the readings, the average monthly consumption was obtained for the whole year.

\subsubsection{Assessment of Energy Consumption Based on the Use of Equipment}

At this stage it was considered the power consumption of each appliance used in the station, depending on the individual hours of utilization. In fact, tracing the consumption of the telecommunications equipment was simple given the type of activity, (strongly continuous) but having a clear picture of the consumption due to the use of air conditioners, on a monthly basis, was not possible because the number of hours of operation of these depends on random variables

Table 1. Energy Consumption in 2008 Using Electricity Bills

\begin{tabular}{|c|c|c|c|c|}
\hline \multicolumn{2}{|c|}{ Bimonthly Intervals } & Bimonthly Consumption (kWh) & Daily Consumption (kWh) & Total Bill (€) \\
\hline \hline $11 / 01 / 2008$ & $08 / 03 / 2008$ & 1,672 & 29.86 & 271.22 \\
\hline $08 / 03 / 2008$ & $08 / 05 / 2008$ & 1,821 & 29.85 & 284.83 \\
\hline $08 / 05 / 2008$ & $09 / 07 / 2008$ & 1,851 & 29.85 & 29.85 \\
\hline $09 / 07 / 2008$ & $08 / 09 / 2008$ & 1,821 & 30.31 & 183.71 \\
\hline $08 / 09 / 2008$ & $08 / 11 / 2008$ & 1,821 & 191.61 \\
\hline $08 / 11 / 2008$ & $11 / 01 / 2009$ & 1,940 & $\mathbf{1 0 , 9 2 6}$ & $\mathbf{1 , 3 4 9 . 4}$ \\
\hline \multicolumn{2}{|c|}{ TOTAL YEAR 2008 } & & & 207.41 \\
\hline
\end{tabular}


such as the temperature outside and inside the technology station.

It was only possible to estimate their annual consumption as the difference between the annual consumption of the radio station broadcasting and various telecommunications equipment, because these have a constant daily consumption as the station functions as a passive node (there is only reception and transmission) and not active node (as in the diffusion plants broadcasting). The power input to each appliance could be traced. The data collected are listed below:

\section{SDH microwave radio}

- 4 USY SDH devices with installed capacity of $100 \mathrm{~W}$ each;

- 2 Add/Drop Multiplexer (ADM) equipment with installed capacity of $150 \mathrm{~W}$ each (multiple);

- An Analog to Digital Converters (ADC) with an apparatus installed capacity of $100 \mathrm{~W}$;

\section{PDH radio}

- 5 PDH devices with installed capacity of $40 \mathrm{~W}$ each;

As said before, these devices operate continuously, then the energy is absorbed is $1 \mathrm{kWh}$ for a total of $8,760 \mathrm{kWh}$ in a year.

Due to air conditioning system, it provides a virtual controller dual probe, allowing the verification of the temperature difference between the environment and the fluid to be cooled.

The instrument detects the ambient temperature and the temperature of the fluid (water) to be cooled, if the air temperature is lower than the temperature of the water to cool, the pilot water system with an appropriate diverter valve (which allows cooling of water cooler using ambient air) in this case realizes a free-cooling cycle. But when the ambient air temperature is warmer than the water to be cooled, the valve diverts water directly on the chiller, bypassing the system of free-cooling and then works in a conventional manner.

Furthermore, this mechanism is regulated by a microprocessor. In the station are installed two Minipac equal air conditioners but programmed differently. They never work together; the first comes into operation when the internal temperature reaches $30{ }^{\circ} \mathrm{C}$ and reduces it to $27{ }^{\circ} \mathrm{C}$, the second comes into operation at $27{ }^{\circ} \mathrm{C}$ and reduces the internal temperature to $24{ }^{\circ} \mathrm{C}$. From the data sheet shows that the power conditioner is installed in each of $1.7 \mathrm{~kW}$.

In conclusion, knowing that the annual consumption of the radio station broadcasting is $10,926 \mathrm{kWh}$ and that the telecommunications equipment absorb $8,760 \mathrm{kWh}$ in a year it is possible to say that $10,926-8,760=2,166 \mathrm{kWh}$ is the annual consumption of air conditioning system which corresponds to about $1,274 \mathrm{~h}$ of operation of the system, whose value was obtained by dividing the annual consumption by the installed power $(1.7 \mathrm{~kW})$.

Although apparently the consumption of radio equipment is higher than that of air conditioners, it has to be noted that the former is practically constant and has lower hourly values than that of the air conditioners, which is noticeably heavier because of the peaks that may occur in correspondence of heat waves during summer. Fig. 1 shows the annual consumption for the transmission radio station.

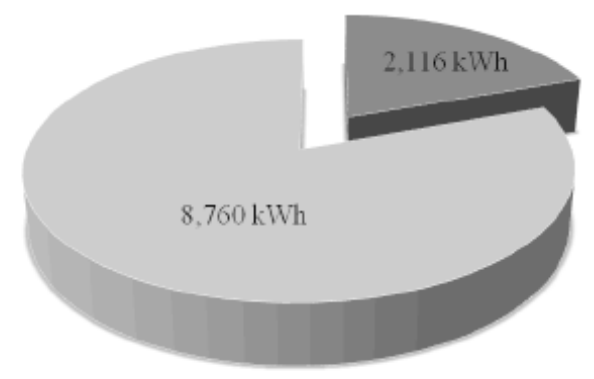

= Annual Consumption of Air-Conditioning System

annual Consumption of Telecommunications Equipment

Fig. (1). Annual transmission radio station consumption.

\section{SELECTING THE MOST SUITABLE RENEWABLE SOURCE FROM SITE FEATURES}

Because of the fact that photovoltaic systems have a very low producibility per square meter, micro-wind turbines were chosen instead. In particular, the choice has been oriented towards a small grid connected wind turbine [2-4].

The wind resource availability is much less predictable than solar, as conditioned by many factors, many of which of local nature (terrain features, presence of obstacles, mountains, hills, buildings, trees etc.).

The source used for the assessment of resource availability in the western area of Sicily is the Italian Wind Atlas, produced by CESI research center and the Department of Physics of the University of Genoa and now available online through a web interface [5]. Fig. 2 shows a map of the specific producibility of Sicily for a height of $50 \mathrm{~m}$ above the ground level (a.g.1.). From the atlas it is possible to draw useful information about the resource distribution. The specific producibility of a wind turbine is intended as the yearly mean producibility divided by its rated power. If the yearly mean producibility is expressed in MW and the rated power is expressed in MW as well, then the specific producibility is expressed in hours and can be interpreted as the equivalent number of hours of operation of the turbine at full rated power. For the Italian Wind Atlas, the specific producibility was obtained taking into account the mean value computed on a group of 15 different commercial wind turbines with hub's height of $50 \mathrm{~m}$ a.g.1. [5].

A large part of the island appears to have resource availability between 1,500 and 2,000 $\mathrm{MWh} / \mathrm{MW}$ installed, while a few areas exceed 3,500 MWh/MW (Mount Etna).

In general, areas near the coast are windier than inland areas and particularly the western area of the island has the highest wind power exploitation potential [3].

Its annual specific producibility varies from a maximum along the coastal area of $3,000 \mathrm{MWh} / \mathrm{MW}$ to a minimum of 2,000 MWh/MW installed.

Therefore in order to obtain a more precise estimate of the likely energy output of a wind turbine in a given site, it is 


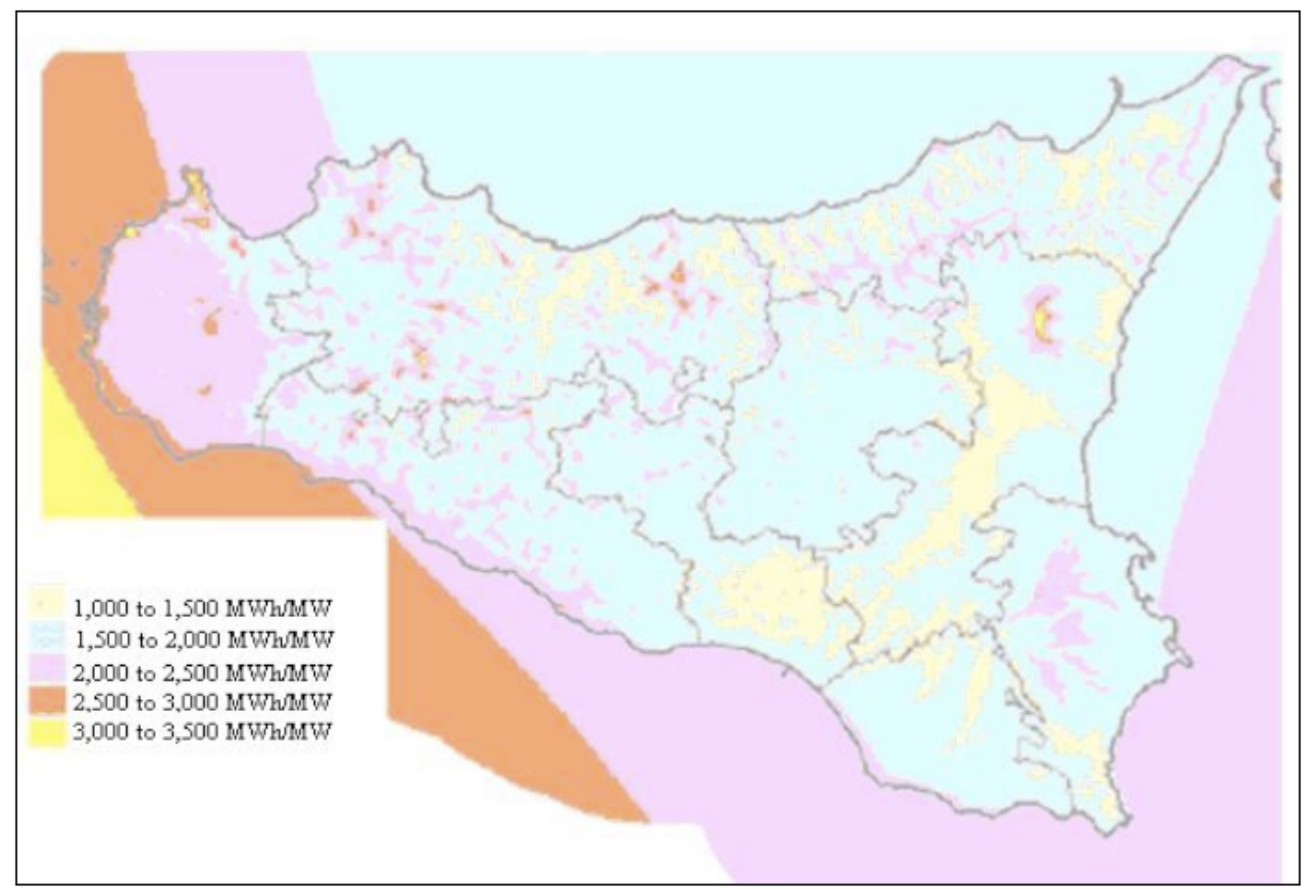

Fig. (2). Map of the specific producibility at $50 \mathrm{~m}$ a.g.1. in Sicily.

important to install a wind measurement station on the site in question (installed on a mast of the height of $10 \mathrm{~m}$ ) and to measure for at least a whole year wind direction and speed. Table 2 provides information on the typical behavior of mini wind turbines (horizontal axis and vertical axis) as a function of the wind intensity $[5,6]$.

The elements that make the source suitable for wind power radio links, are:

- Economically cheaper than photovoltaic;

- Very low maintenance requirements (and programming);

- Robustness;

- Long life expectancy;
- No storage system.

The disadvantages are:

- The resource availability is highly dependent on wind conditions of the site;

- Resource development with seasonal variations and therefore stochastic (probabilistic);

- Possibility of occurrence of prolonged periods with no wind;

- Moving parts;

- No power is generated if the wind speed is below the cut-in speed;

- Requires an inverter.

Table 2. Typical Behavior of Mini Wind Turbines (Horizontal and Vertical Axis)

\begin{tabular}{|c|c|}
\hline Windiness Typical value & Aerogenerator reply \\
\hline \hline $0-2 \mathrm{~m} / \mathrm{s}$ & Zero rotation \\
\hline $2-4 \mathrm{~m} / \mathrm{s}$ & Beginning of the rotation, generation=0 \\
\hline $4-6 \mathrm{~m} / \mathrm{s}$ & Beginning of the generation \\
\hline Annual average $<5 \mathrm{~m} / \mathrm{s}$ & Unsuitable site (insufficient energy output) \\
\hline Annual average $=5-6 \mathrm{~m} / \mathrm{s}$ & Quite good site (sufficient energy output) \\
\hline Annual average $=7-9 \mathrm{~m} / \mathrm{s}$ & Good site \\
\hline $20 \mathrm{~m} / \mathrm{s}$ & Maximum power \\
\hline $25-30 \mathrm{~m} / \mathrm{s}$ & No power production \\
\hline $40-50 \mathrm{~m} / \mathrm{s}$ & Damage danger \\
\hline
\end{tabular}




\subsection{Producibility of the Turbine}

A data acquisition campaign was carried out in 2008, also to calculate the monthly average values of wind speed with and without calm periods (zero wind speed values).

The percentages of data coverage are calculated to determine the significance of the data, as it is necessary this percentage to be higher than $85 \%$ in order the month to be deemed significant.

Subsequently, hourly wind speed data (acquired from the station anemometer in 2008) were split and organized into speed classes with a width of $0.5 \mathrm{~m} / \mathrm{s}$ from the class of 0.5 $\mathrm{m} / \mathrm{s}$ up to the class of $38 \mathrm{~m} / \mathrm{s}$.

Having the wind speed data available, the two main probability density functions (pdf's) used to characterize the wind speed distribution in a site are the Weibull and Rayleigh pdf's.

There exist two theories based on statistical probability of occurrence of a certain intensity of wind over a period of time [6-8]. Between these two functions the one that approximates better the distribution of wind speed is the Weibull distribution function for the most of the sites.

The wind speed data acquired through the measurement campaign contained a large number of calms.

This represented a problem, mainly because when a Weibull distribution is estimated from a data series with a significant number of calms the fitting procedure will produce a more conservative estimate, which is usually not a good approximation of the distribution of wind data in the frequency range relevant to wind energy production.

In order to solve this problem, we applied a method described by Mulugetta and Drake (1996) in which a Weibull distribution is fit to the observed wind speed data that are higher than $0 \mathrm{~m} / \mathrm{s}$, while calms are considered separately [9].

Knowing the probability density of the wind speed for each class of speed, from $0.5 \mathrm{~m} / \mathrm{s}$ to $38 \mathrm{~m} / \mathrm{s}$, it was possible to find the corresponding Weibull frequency distribution that takes also calms into account (see Table 3). As a result, the Weibull distribution was drawn (Fig. (3)).

\section{ESTIMATION OF THE PRODUCIBILITY OF THE TURBINE}

Multiplying the theoretical Weibull frequency on each class of wind speed, referred to the year with calm (by the corrective coefficient), by the number of hours per year, the annual total number of events per class of wind speed can be calculated, i.e. the absolute frequency for each speed class. From the power curve provided by the turbines' manufacturers it was subsequently obtained, through a linear interpolation, the power generated in each speed range from 0 to 25 $\mathrm{m} / \mathrm{s}$, i.e. the "measured power curve".

The "measured power curve" was then compared with the rated power curve provided by the manufacturer. Multiplying the power in $\mathrm{kW}$ associated with the $i$-th speed class (obtained from the "measured power curve") and the absolute frequency referred to the same frequency bin (i.e. of the $i$-th interval)and expressed in hours/year, it was possible to obtain the annual energy produced for each speed class.
Summing up the energy output obtained for each speed class the total producibility for the year 2008 was obtained for the generic wind turbine. This quantity was then multiplied by a correction factor equal to 0.90 to take into account the periods of plant shutdown due to normal maintenance, and can disconnect from the power supply to overload the same problems.

Afterward we calculated the producibility of each turbine considered in this study and we created histograms to compare the energy output from different turbines, arranged in power classes. Tables 4, 5 show data to calculate the energy produced by a turbine (especially Ropatec Maxi Vertical 6 $\mathrm{kW})$.

As said above, the correction coefficient (c.f.) used in Table 5 to obtain the corrected value of the total energy produced is equal to 0.9 .

\section{COMPARISON OF ANNUAL PRODUCIBILITY OF THE TURBINES}

We calculated the electric energy production for different vertical and horizontal axis turbines with a rated power between 3 and $6 \mathrm{~kW}$. From Fig. (4), we can see that the horizontal axis turbine that produces more energy in 2008 is the Bornary, while the vertical axis one is the Cleanfield V3.5. Considering that the annual energy requirement of the radio station broadcasting is about $10.9 \mathrm{MWh}$ it is clear that all the horizontal axis turbines listed below are able to meet the load required by Station:

- Bornary with producibility of $12.86 \mathrm{MWh}$;

- Four Seasons with producibility of $11.02 \mathrm{MWh}$;

- Whisper 500, with producibility of $11.46 \mathrm{MWh}$.

On the other hand, among the vertical axis turbines, only the Cleanfield V3.5 turbine can meet the required load, with a producibility of $11.13 \mathrm{MWh}$.

From Fig. (5), we can see that the horizontal axis turbine that produces more energy in 2008 is the Conergy Swt, while the vertical axis turbine one is the Ropatec Maxi Vertical. Considering that the annual energy requirements of the radio station broadcasting is about $10.9 \mathrm{MWh}$ it is clear that all the available turbines can meet the required load.

\section{DESCRIPTION OF THE COMPENSATION MEAS- URES ADOPTED}

The impact of birds on the blades of wind turbine is due to the transparency of these when they reach high speed (400 $\mathrm{rpm})$. For horizontal axis wind turbines with a rated power of 3 and $6 \mathrm{KW}$, the rotation speed at full working regime is between 200 and $400 \mathrm{rpm}$, while for vertical axis turbines of the same rated power, the rotation speed is in the range $150 \div 190 \mathrm{rpm}$.

In order to further reduce the risk of birds impact on the blades of wind turbines we chose to install a vertical axis turbine. If you choose to use a turbine with a rated power of $6 \mathrm{~kW}$ to be used is the Ropatec Maxi Vertical; the only aspect that may be significant in assessing the incidence of this diameter, equal to $4.70 \mathrm{~m}$. 
Table 3. Weibull Frequency

\begin{tabular}{|c|c|c|c|c|c|}
\hline Velocity [m/s] & $\mathbf{f}(\mathbf{v})$ & Velocity $[\mathrm{m} / \mathrm{s}]$ & $\mathbf{f}(\mathbf{v})$ & Velocity $[\mathrm{m} / \mathrm{s}]$ & $\mathbf{f}(\mathbf{v})$ \\
\hline 0.5 & 0,0078 & 13.5 & 0.0184 & 26.5 & 0.0018 \\
\hline 1 & 0,0122 & 14 & 0.0173 & 27 & 0.0016 \\
\hline 1.5 & 0,0158 & 14.5 & 0.0163 & 27.5 & 0.0014 \\
\hline 2 & 0,0187 & 15 & 0.0152 & 28 & 0.0012 \\
\hline 2.5 & 0,0212 & 15.5 & 0.0142 & 28.5 & 0.0011 \\
\hline 3 & 0,0232 & 16 & 0.0132 & 29 & 0.0010 \\
\hline 3.5 & 0,0249 & 16.5 & 0.0123 & 29.5 & 0.0008 \\
\hline 4 & 0,0263 & 17 & 0.0114 & 30 & 0.0007 \\
\hline 4.5 & 0,0274 & 17.5 & 0.0105 & 30.5 & 0.0006 \\
\hline 5 & 0.0282 & 18 & 0.0097 & 31 & 0.0006 \\
\hline 5.5 & 0.0287 & 18.5 & 0.0089 & 31.5 & 0.0005 \\
\hline 6 & 0.0290 & 19 & 0.0082 & 32 & 0.0004 \\
\hline 6.5 & 0.0291 & 19.5 & 0.0075 & 32.5 & 0.0004 \\
\hline 7 & 0.0291 & 20 & 0.0069 & 33 & 0.0003 \\
\hline 7.5 & 0.0288 & 20.5 & 0.0063 & 33.5 & 00003 \\
\hline 8 & 0.0284 & 21 & 0.0057 & 34 & 0.0002 \\
\hline 8.5 & 0.0278 & 21.5 & 0.0052 & 34.5 & 0.0002 \\
\hline 9 & 0.0272 & 22 & 0.0047 & 35 & 0.0002 \\
\hline 9.5 & 0.0264 & 22.5 & 0.0042 & 35.5 & 0.0002 \\
\hline 10 & 0.0256 & 23 & 0.0038 & 36 & 0.0001 \\
\hline 10.5 & 0.0246 & 23.5 & 0.0034 & 36.5 & 0.0001 \\
\hline 11 & 0.0237 & 24 & 0.0031 & 37 & 0.0001 \\
\hline 11.5 & 0.0227 & 24.5 & 0.0028 & 37.5 & 0.0001 \\
\hline 12 & 0.0216 & 25 & 0.0025 & 38 & 0.0001 \\
\hline 12.5 & 0.0205 & 25.5 & 0.0022 & & \\
\hline 13 & 0.0195 & 26 & 0.0020 & & \\
\hline
\end{tabular}

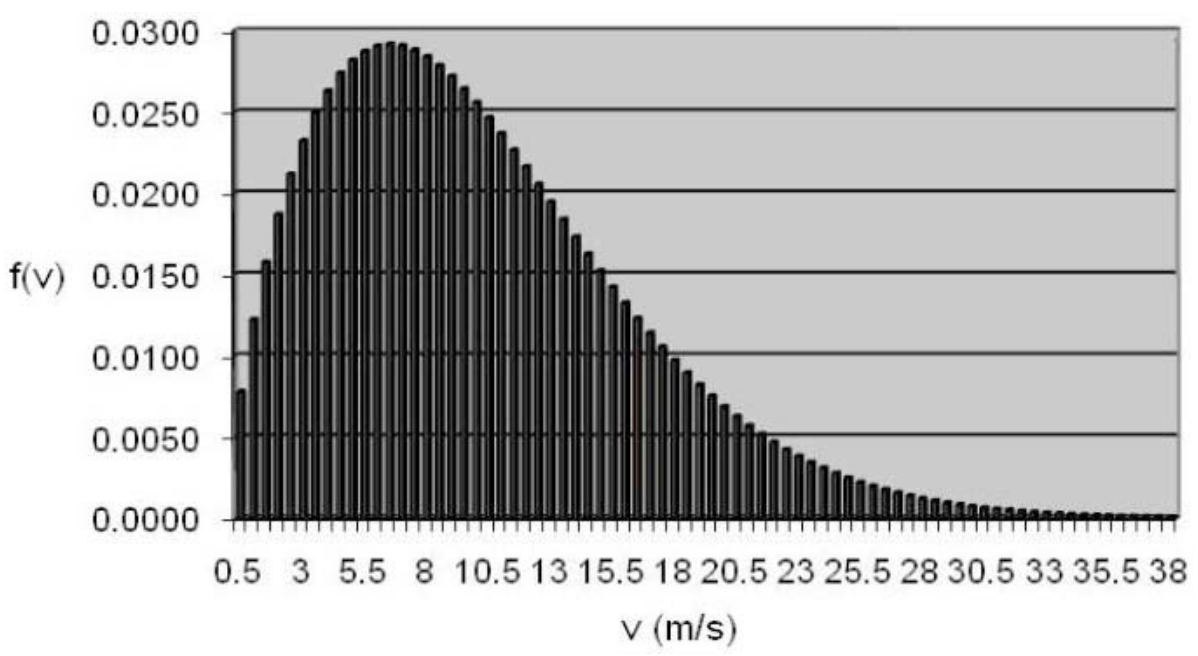

Fig. (3). Weibull diagram distribution frequency. 
Table 4. Annual Producibility - Ropatec Maxi Vertical Turbine (6 kW)

\begin{tabular}{|c|c|c|c|c|c|c|c|}
\hline $\begin{array}{c}\text { Classes } \\
(\mathbf{m} / \mathbf{s})\end{array}$ & $\begin{array}{c}\text { Power } \\
(k W)\end{array}$ & $\begin{array}{c}\text { Absolute frequency } \\
\text { (hours/year) }\end{array}$ & $\begin{array}{l}\text { Energy } \\
(\mathbf{k W h})\end{array}$ & $\begin{array}{c}\text { Classes } \\
(\mathrm{m} / \mathbf{s})\end{array}$ & $\begin{array}{c}\text { Power } \\
(k W)\end{array}$ & $\begin{array}{c}\text { Absolute frequency } \\
\text { (hours/year) }\end{array}$ & $\begin{array}{r}\text { Energy } \\
(\mathrm{kWh})\end{array}$ \\
\hline 0 & 0 & 0 & 0 & 6.5 & 0.65 & 255.29 & 165.94 \\
\hline 0.5 & 0 & 68.25 & 0 & 7 & 0.8 & 254.55 & 203.64 \\
\hline 1 & 0 & 107.10 & 0 & 7.5 & 0.95 & 252.30 & 239.68 \\
\hline 1.5 & 0 & 138.02 & 0 & 8 & 1.1 & 248.70 & 273.57 \\
\hline 2 & 0 & 163.71 & 0 & 8.5 & 1.3 & 243.92 & 317.09 \\
\hline 2.5 & 0.05 & 185.29 & 9.26 & 9 & 1.5 & 238.10 & 357.16 \\
\hline 3 & 0.1 & 203.33 & 20.33 & 9.5 & 1.8 & 231.40 & 416.53 \\
\hline 3.5 & 0.15 & 218.23 & 32.73 & 10 & 2.1 & 223.96 & 470.31 \\
\hline 4 & 0.2 & 230.28 & 46.06 & 10.5 & 2.5 & 215.90 & 539.75 \\
\hline 4.5 & 0.3 & 239.72 & 71.92 & 11 & 2.9 & 207.35 & 601.32 \\
\hline 5 & 0.4 & 246.75 & 98.70 & 11.5 & 3.4 & 198.43 & 674.66 \\
\hline 5.5 & 0.45 & 251.56 & 113.20 & 12 & 3.9 & 189.24 & 738.04 \\
\hline 6 & 0.5 & 254.35 & 127.18 & 12.5 & 4.4 & 179.88 & 791.49 \\
\hline
\end{tabular}

Table 5. Annual Producibility - Ropatec Maxi Vertical Turbine (6 kW)

\begin{tabular}{|c|c|c|c|c|c|c|c|}
\hline $\begin{array}{c}\text { Classes } \\
(\mathrm{m} / \mathrm{s})\end{array}$ & $\begin{array}{c}\text { Power } \\
(k W)\end{array}$ & $\begin{array}{c}\text { Absolute frequency } \\
\text { (hours/year) }\end{array}$ & $\begin{array}{c}\text { Energy } \\
(k W h)\end{array}$ & $\begin{array}{c}\text { Classes } \\
(\mathbf{m} / \mathbf{s})\end{array}$ & $\begin{array}{c}\text { Power } \\
(k W)\end{array}$ & $\begin{array}{c}\text { Absolute frequency } \\
\text { (hours/year) }\end{array}$ & $\begin{array}{c}\text { Energy } \\
(k W h)\end{array}$ \\
\hline 13 & 4.9 & 170.45 & 835.19 & 19.5 & 5.8 & 65.83 & 381.82 \\
\hline 13.5 & 5.4 & 161.01 & 869.45 & 20 & 5.8 & 60.14 & 348.84 \\
\hline 14 & 5.9 & 151.64 & 894.69 & 20.5 & 5.8 & 54.83 & 318.00 \\
\hline 14.5 & 5.9 & 142.41 & 840.22 & 21 & 5.8 & 49.87 & 289.26 \\
\hline 15 & 5.9 & 133.37 & 786.86 & 21.5 & 5.8 & 45.27 & 262.55 \\
\hline 15.5 & 5.85 & 124.56 & 728.65 & 22 & 5.8 & 41.00 & 237.80 \\
\hline 16 & 5.8 & 116.02 & 672.91 & 22.5 & 5.8 & 37.06 & 214.93 \\
\hline 16.5 & 5.8 & 107.79 & 625.16 & 23 & 5.8 & 33.42 & 193.86 \\
\hline 17 & 5.8 & 99.89 & 579.33 & 23.5 & 5.8 & 30.09 & 174.50 \\
\hline 17.5 & 5.8 & 92.33 & 535.53 & 24 & 5.8 & 27.03 & 156.76 \\
\hline 18 & 5.8 & 85.14 & 493.84 & 24.5 & 5.8 & 24.23 & 140.55 \\
\hline 18.5 & 5.8 & 78.33 & 454.31 & 25 & 5.8 & 21.68 & 125.76 \\
\hline \multirow[t]{3}{*}{19} & 5.8 & 71.89 & 416.97 & 25.5 & 0 & 19.36 & 0 \\
\hline & & & & & & Tot. kWh/year & $17,886.31$ \\
\hline & & & & & & c.f. xTot kWh/year & $16,097.67$ \\
\hline
\end{tabular}




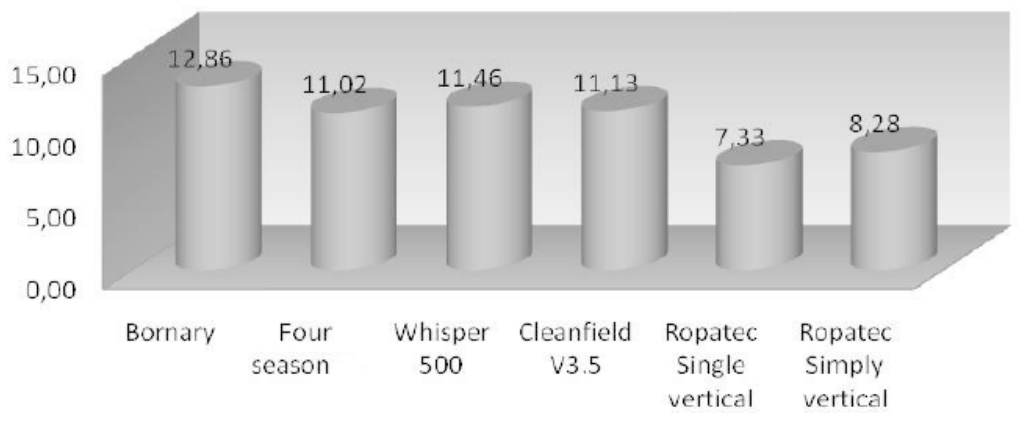

Fig. (4). Producibility of $3 \mathrm{~kW}$ turbines (MWh/year).

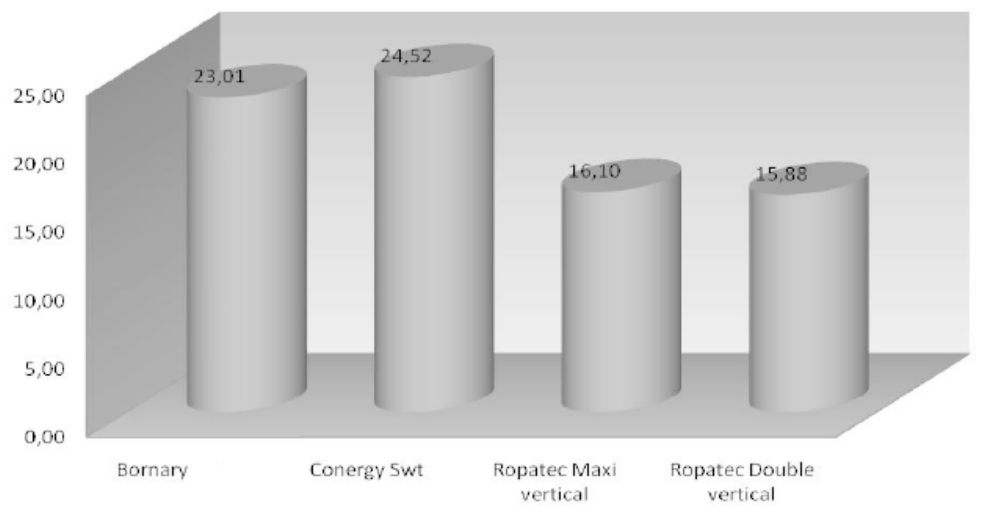

Fig. (5). Producibility of $6 \mathrm{~kW}$ turbines (MWh/year).
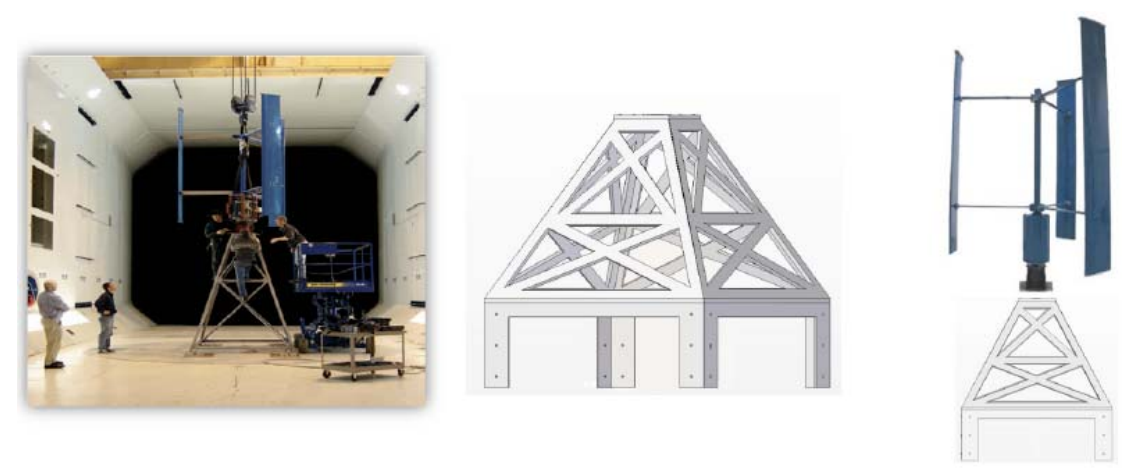

Fig. (6). Mechanical design of the tower.

This problem can be minimized installing the V3.5 Cleanfield turbine (rated power equal to $3.5 \mathrm{~kW}$ ), which still manages to meet the energy needs of radio broadcasting station. In this case the diameter is equal to $2.75 \mathrm{~m}$, certainly more suitable for the selected site.

The choice of the vertical axis is optimal also from the technical standpoint for the chosen broadcasting site, considering that the vertical axis turbine, compared to the horizontal axis one, implies less safety issues for the operators and a negligible magnetical interference on the radio signals.

\section{SOLUTION DESIGN}

The wind turbine is coupled to the generator which produces alternating current whose frequency and voltage is not constant because of the variable speed. For this reason the energy thus obtained can not be introduced directly into the electricity grid. In order to inject into the grid electricity with the appropriate features the generator is thus connected to a three-phase electronic converter (inverter), which generates electric energy with the following features: amplitude of the rated voltage of $220 \mathrm{~V}$; frequency of $50 \mathrm{~Hz}$ and current out of phase by $180^{\circ}$ with the tension and form dependent on instantaneous production.

The output of the inverter is connected to a filter made by the high value inductors, with the aim of minimizing the harmonics and obtaining an output waveform as close as possible to a sine wave. The plant will be equipped with a protection device which is necessary in the case of a failure or malfunction in the distribution network (interface device). This system is able to automatically disconnect the turbine when the voltage or main frequency deviate from the nominal values or when there is an interruption of electricity supply. The turbine will also be equipped with a safety switch.

The structure in which the turbine will be anchored to the frame of the radio station is showed in Fig. (6), which is a truss structure with the shape of a truncated regular pyramid. 


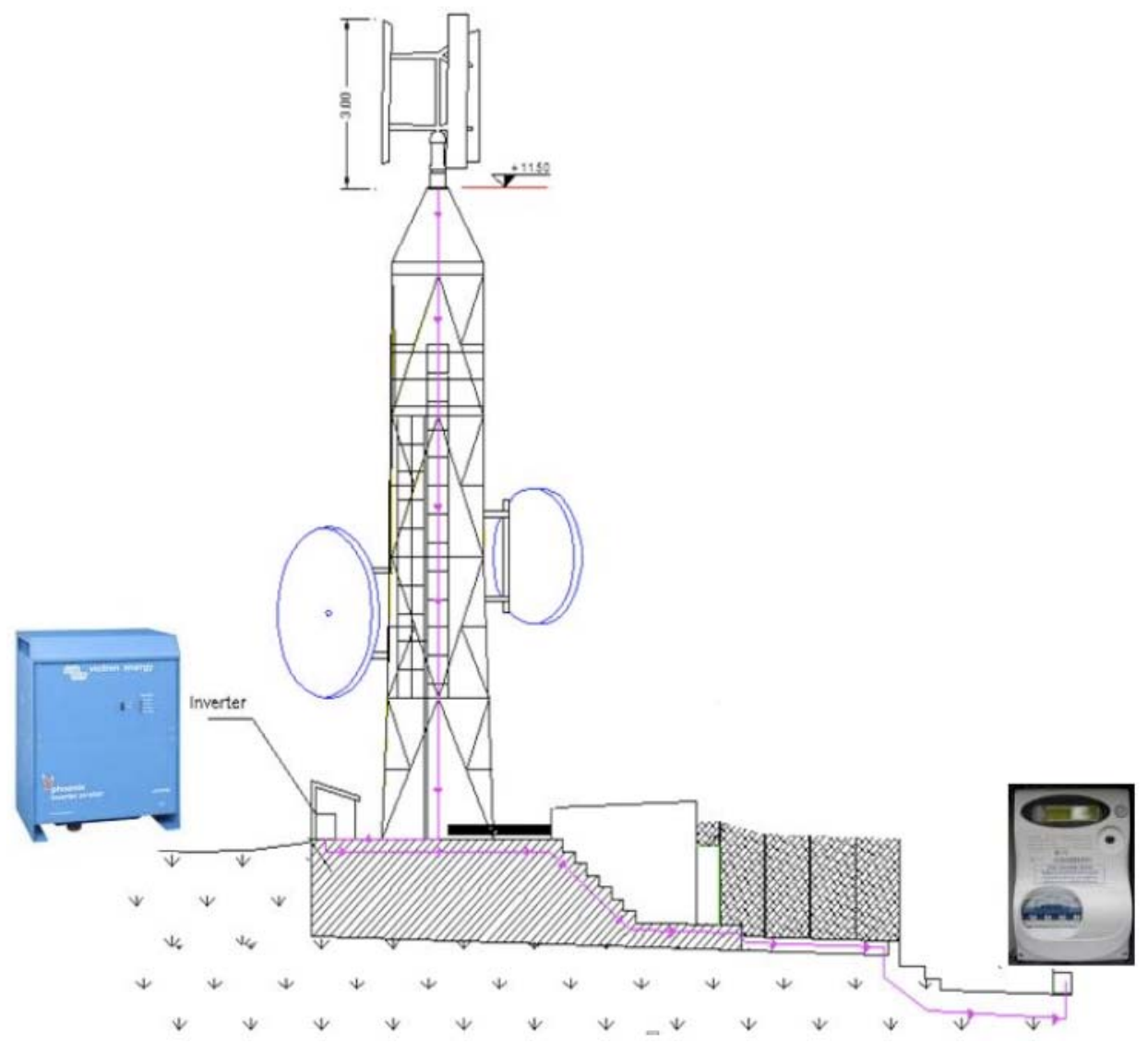

Fig. (7). Layout of proposed solution.

The cost of the structure including the anchoring system was estimated at $€ 3,500$.

Fig. (7) shows a layout of the entire system. The pink line represents the electrical wires in a qualitative way. In Fig. (8) it is reported a simulation of the tower before and after vertical axis turbine installation.

\section{CONCLUSIONS}

The primary purpose of this work is to find a solution exploiting a low power wind turbine to supply a real telecom-

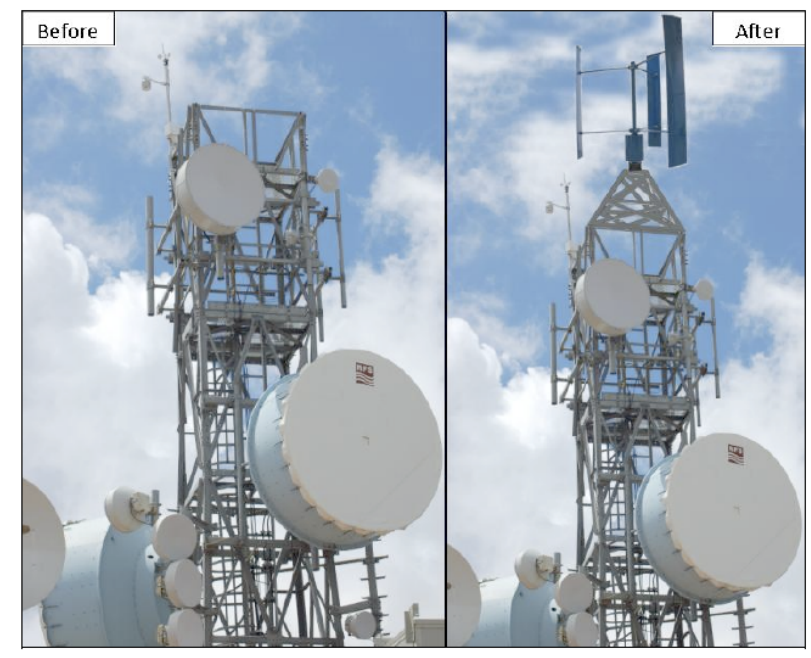

Fig. (8). Tower before and after vertical axis turbine installation. munication site located near Palermo, the main city of Sicily (Italy). The secondary but still important goal was to devise a solution associated with low carbon emissions. The choice of the plant has been made by checking all the major advantages and disadvantages of producing energy from small wind and photovoltaic systems, taking into account the particular characteristics of the site in question. Given the presence of the electricity grid it was chosen a grid-connected system, thus avoiding the additional cost of the storage equipment, needed for stand-alone systems.

Subsequently, in order to choose between mini wind turbine and photovoltaic system, the available space was taken into consideration. With this constraint in mind, it is evident that the space available with a photovoltaic system would only allow the installation of $1 \mathrm{~kW}$ of power.

In addition, this surface is oriented to the south but the presence of obstacles (towers) would in almost every period of the year always cast shadow on the panels, significantly reducing the efficiency of the broadcasting system. For this reason, given the fine wind potential of the site considered in this study, the chosen solution is a mini-eolic plant, which will be installed on the station's truss higher that all the parables thus not interfering with their transmission.

The next step was the installation of an anemometer station on the mast at $12 \mathrm{~m}$ above the ground level (a.g.1.), which acquired wind speed data for of the whole year 2008 . At the end of the data acquisition campaign, the data have 
been used to derive the Weibull probability density function for the site in question.

Subsequently, knowing the power curves of the chosen mini-wind turbines, it was possible to estimate their annual energy producibility. The turbines were divided into classes of power, and for each class vertical axis turbines were compared with horizontal axis ones. The type of turbine was chosen based on:

- its annual nominal power production;

- environmental criteria (carbon emissions avoided allowed by the use of the turbine);

- results of a cost benefit analysis.

The finding of the study was that all the horizontal axis turbines can supply the energy needs of the radio broadcasting station, that amounts to approximately $10,926 \mathrm{kWh} /$ year. On the other hand, not all the vertical axis turbines can produce the required electric energy; only some models like the $3.5 \mathrm{~kW}$ Cleanfield and the $6 \mathrm{~kW}$ vertical axis Ropatec Max can satisfy the electric energy demand.

The environmental impacts of this system on flora are negligible, while the impacts on wildlife are connected with a possible obstruction of birds flights paths due to the turbine blades. To reduce this kind of impact we have chosen a ver- tical axis turbine (the Cleanfield $3.5 \mathrm{~kW}$ turbine), whose rotation speed is lower than a turbine with horizontal axis thus reducing the risk of impact to the birds life.

\section{REFERENCES}

[1] Bayod-Rùjula, A.A. Future development of the electricity systems with distributed generation. Energy 2009, 34(3), 377-383.

[2] Morthorst, P.E. Capacity development and profitability of wind turbines. Energy Policy 1999, 27(13), 779-787.

[3] Varol, A.; Ilkilic, C.; Varol, Y. Increasing the efficiency of wind turbines. Journal of Wind Engineering and Industrial Aerodynamics 2001, 89(9), 809-815.

[4] Clause, P.D.; Wood, D.H. Research and development issues for small wind turbines. Renewable Energy 1999, 16(1-4), 922-927.

[5] CESI \& Università degli Studi di Genova - Dipartimento di Fisica Ricerca di Sistema per il settore elettrico, Progetto ENERIN: Atlante eolico dell'Italia; 2002. http://atlanteeolico.cesiricerca.it; last acces on July 2009.

[6] Wright, A.K.; Wood, D.H. The starting and low wind speed behaviour of a small horizontal axis wind turbine. Journal of Wind Engineering and Industrial Aerodynamics 2004, 92(14-15), 1265-1279.

[7] Mayer, C.; Bechly, M.E.; Hampsey, M.; Wood, D.H. The starting behaviour of a small horizontal-axis wind turbine. Renewable Energy 2001, 22(5), 411-417.

[8] Ozgener, O. A small wind turbine system (SWTS) application and its performance analysis. Energy Conversion and Management 2006, 47(11-12), 132-1337.

[9] Mulugetta, Y.; Drake, F. Assessment of solar and wind energy resources in Ethiopia. II. Wind energy. Solar Energy 1996, 57(4), $323-334$.

(C) Messineo et al.; Licensee Bentham Open.

This is an open access article licensed under the terms of the Creative Commons Attribution Non-Commercial License (http://creativecommons.org/licenses/by-nc/3.0/) which permits unrestricted, non-commercial use, distribution and reproduction in any medium, provided the work is properly cited. 